Case Reports
in Dermatology

\title{
Use of Anti-IL-17 Monoclonal Antibodies in HIV Patients with Erythrodermic Psoriasis
}

\author{
Mary Catherine G. Pangilinan ${ }^{\mathrm{b}} \quad$ Peerada Sermswan $^{\mathrm{a}} \quad$ Pravit Asawanonda $^{\mathrm{a}}$ \\ aDivision of Dermatology, Department of Medicine, Faculty of Medicine, Chulalongkorn \\ University, Bangkok, Thailand; 'Department of Dermatology Research Institute for \\ Tropical Medicine in Alabang, Muntinlupa City, Philippines
}

\section{Keywords}

Erythrodermic psoriasis · HIV psoriasis · Anti-IL-17 · Biologic treatment · Ixekizumab · Secukinumab

\begin{abstract}
Psoriasis is an immune-mediated skin disease with various presentations. HIV infection affects the immune system and aggravates psoriasis lesions. Therefore, psoriasis management in HIV patients poses a great challenge for dermatologists. In this report, 2 HIV patients with erythrodermic psoriasis received anti-IL-17 and experienced significant clearance of lesions. No recurrence or opportunistic infection was noted. In conclusion, anti-IL-17 monoclonal antibodies are an effective and promising treatment option for HIV-infected patients with psoriasis.
\end{abstract}

(C) 2020 The Author(s)

Published by S. Karger AG, Basel

\section{Introduction}

Psoriasis is an immune-mediated inflammatory skin disease with various presentations. HIV patients may present with more severe or atypical forms of psoriasis. Multiple morphologies can co-exist in an HIV patient due to immune dysregulation [1]. Although plaque-type psoriasis is by far the most common type, other relatively rare subtypes such as erythrodermic, inverse, and acral psoriasis appear more frequently in HIV patients [2]. 


\section{Case Reports in Dermatology}

\begin{tabular}{l|l}
\hline Case Rep Dermatol 2020;12:132-137 \\
\hline DOI: 10.1159/000508781 & $\begin{array}{l}\text { @ 2020 The Author(s). Published by S. Karger AG, Basel } \\
\text { www.karger.com/cde }\end{array}$ \\
\hline
\end{tabular}

Pangilinan et al.: Anti-IL-17 Monoclonal Antibodies for Erythrodermic Psoriasis in HIV

Biologics have significantly changed the landscape of psoriasis treatment [3]. However, some physicians may hesitate to prescribe them for patients with both erythrodermic psoriasis and HIV infection. Data regarding treatment of erythrodermic psoriasis with biologics in HIV patients are still lacking. We hereby present 2 cases of erythrodermic psoriasis in HIV patients treated with anti-IL-17 monoclonal antibody.

\section{Case 1}

Our first case is a 60-year-old Thai male with a 7-year history of multiple erythematous scaly plaques, which later changed in morphology and became more erythematous and extensive shortly after presentation. The patient was diagnosed with HIV infection with CD4 $=170$, viral load $<20$. At the time he was examined, he was taking efavirenz $600 \mathrm{mg} /$ day, tenofovir $300 \mathrm{mg} /$ day, lamivudine $300 \mathrm{mg} /$ day, simvastatin, and co-trimoxazole. No topical or systemic treatments for psoriasis were used. Upon physical examination, typical psoriatic plaques covering more than $90 \%$ of the body surface area with a Psoriasis Area and Severity Index (PASI) score of 36 were noted. Nail dystrophy and hair loss were also present (Fig. 1).

Initially, he was given acitretin $25 \mathrm{mg}$ /day on alternate days for 2 weeks. Follow-up examination showed no significant improvement of lesions. Baseline laboratories were obtained, and all were within normal limits with negative Quantiferon Gold for TB test, negative HBsAg, anti-HBs, anti HCV, and positive anti-HBc. His chest X-ray was normal. Because of debilitating disease prohibiting him from working, a single dose of ixekizumab $80 \mathrm{mg}$ was administered. After 2 weeks, a PASI score was 5 . After 7 weeks, significant clearance of the lesions and no flare-up was observed (Fig. 2). The patient continued taking low-dose acitretin $25 \mathrm{mg}$ every other day along with $0.1 \%$ triamcinolone acetonide cream, with sustained improvement after several months.

\section{Case 2}

The second case was a 31-year-old HIV-infected Thai male with a 7-year history of erythroderma. At the time he was examined, he was undergoing highly active antiretroviral therapy with undetectable viral loads. He responded well to methotrexate treatment for erythroderma before but discontinued using it. No topical or systemic treatments for psoriasis were used at the time of presentation. Upon physical examination, generalized erythema with a PASI score of 24 was noted.

The patient was then started with secukinumab 300-mg subcutaneous injection after proper screening. The on-label protocol including induction doses was used in this patient. Improvement was noted after 1 week with a PASI score of 12 . After 4 doses of secukinumab $300 \mathrm{mg}$, PASI 100, or total clearance, was achieved and maintained throughout the injection period even after dosage reduction to $150 \mathrm{mg}$ monthly after the 7th dose. After 3 doses, neither recurrences nor opportunistic infections were observed. He was then treated with secukinumab 150-mg injection every 4 weeks until present. His baseline as well as follow-up laboratory work-ups were within normal limits. 


\section{Case Reports in Dermatology}

\begin{tabular}{l|l}
\hline Case Rep Dermatol 2020;12:132-137 \\
\hline DOI: 10.1159/000508781 & $\begin{array}{l}\text { @ 2020 The Author(s). Published by S. Karger AG, Basel } \\
\text { www.karger.com/cde }\end{array}$ \\
\hline
\end{tabular}

Pangilinan et al.: Anti-IL-17 Monoclonal Antibodies for Erythrodermic Psoriasis in HIV

\section{Discussion}

HIV infection is a risk factor for psoriasis development [4]. Moreover, in HIV patients, CD4 levels also have an important role in the development and progression of psoriasis. Patients with CD4 levels $<200 \times 10^{6}$ cells/L are prone to develop psoriasis [5]. It can be assumed that HIV patients may experience a more severe form of psoriasis. Both our patients' lesions became more aggressive when HIV infection was detected. In many seropositive individuals, psoriasis improves upon antiretroviral therapy. However, in our two patients, despite adequate control of the viral loads, psoriasis did not improve.

According to the British Association of Dermatologists (BAD) guidelines, biologics could be used cautiously in HIV patients with moderate to severe psoriasis, provided that HIV is adequately treated and monitored [6]. The American Academy of Dermatology and National Psoriasis Foundation (AAD-NPF) guidelines also suggested that anti-IL-17 monoclonal antibodies can be used in HIV patients who are receiving antiretroviral therapy and having their viral loads under control [3]. Other biologics such as ustekinumab and infliximab were effective in HIV psoriasis as well [7]. Among the various classes of biologics, anti-IL-17 seems relatively safer as IL-17 is a "peripheral" cytokine in psoriasis pathomechanisms. It is of note that in the first patient, only one "half dose" of ixekizumab was used as an "add-on" treatment with rapid and dramatic improvement, allowing conventional treatment with acitretin to exert its efficacy.

\section{Conclusion}

The cases we have presented are representatives of HIV patients with erythrodermic psoriasis who experienced great improvement of PASI after using anti-IL-17A monoclonal antibody, suggesting that both secukinumab and ixekizumab may be a promising treatment for erythrodermic psoriasis in HIV patients.

\section{Acknowledgement}

We would like to express our appreciation to Dr. Nattapon Ngarmjiratam for his valuable insight on the patients' condition.

\section{Statement of Ethics}

The study was conducted under the tenets of the Declaration of Helsinki. Written informed consent to publish their cases including publication of images was obtained.

\section{Conflict of Interest Statement}

The authors declare that there are no conflicts of interest regarding the publication of this article. 


\section{Case Reports in Dermatology}

\section{Funding Sources}

This article received no funding.

\section{Author Contributions}

Mary Catherine G. Pangilinan, MD, collected the data. Peerada Sermswan, MD, wrote the manuscript with support from Dr. Pravit Asawanonda. Pravit Asawanonda, MD, DSc, provided medical care for the patients and supervised the work.

\section{References}

1 Obuch ML, Maurer TA, Becker B, Berger TG. Psoriasis and human immunodeficiency virus infection. J Am Acad Dermatol. 1992 Nov;27(5 Pt 1):667-73.

2 Morar N, Dlova N, Gupta AK, Naidoo DK, Aboobaker J, Ramdial PK. Erythroderma: a comparison between HIV positive and negative patients. Int J Dermatol. 1999 Dec;38(12):895-900.

3 Menter A, Strober BE, Kaplan DH, Kivelevitch D, Prater EF, Stoff B, et al. Joint AAD-NPF guidelines of care for the management and treatment of psoriasis with biologics. J Am Acad Dermatol. 2019 Apr;80(4):1029-72.

4 Yen YF, Jen IA, Chen M, Lan YC, Lee CY, Chuang PH, et al. HIV Infection Increases the Risk of Incident Psoriasis: A Nationwide Population-Based Cohort Study in Taiwan. J Acquir Immune Defic Syndr. 2017 Aug;75(5):493-9.

5 Goh BK, Chan RK, Sen P, Theng CT, Tan HH, Wu YJ, et al. Spectrum of skin disorders in human immunodeficiency virus-infected patients in Singapore and the relationship to CD4 lymphocyte counts. Int J Dermatol. 2007 Jul;46(7):695-9.

6 Smith CH, Jabbar-Lopez ZK, Yiu ZZ, Bale T, Burden AD, Coates LC, et al. British Association of Dermatologists guidelines for biologic therapy for psoriasis 2017. Br J Dermatol. 2017 Sep;177(3):628-36.

7 Nakamura M, Abrouk M, Farahnik B, Zhu TH, Bhutani T. Psoriasis treatment in HIV-positive patients: a systematic review of systemic immunosuppressive therapies. Cutis. 2018 Jan;101(1):38;42;56. 
Case Reports in Dermatology
Case Rep Dermatol 2020;12:132-137

DOI: $10.1159 / 000508781$

(c) 2020 The Author(s). Published by S. Karger AG, Basel www.karger.com/cde

Pangilinan et al.: Anti-IL-17 Monoclonal Antibodies for Erythrodermic Psoriasis in HIV
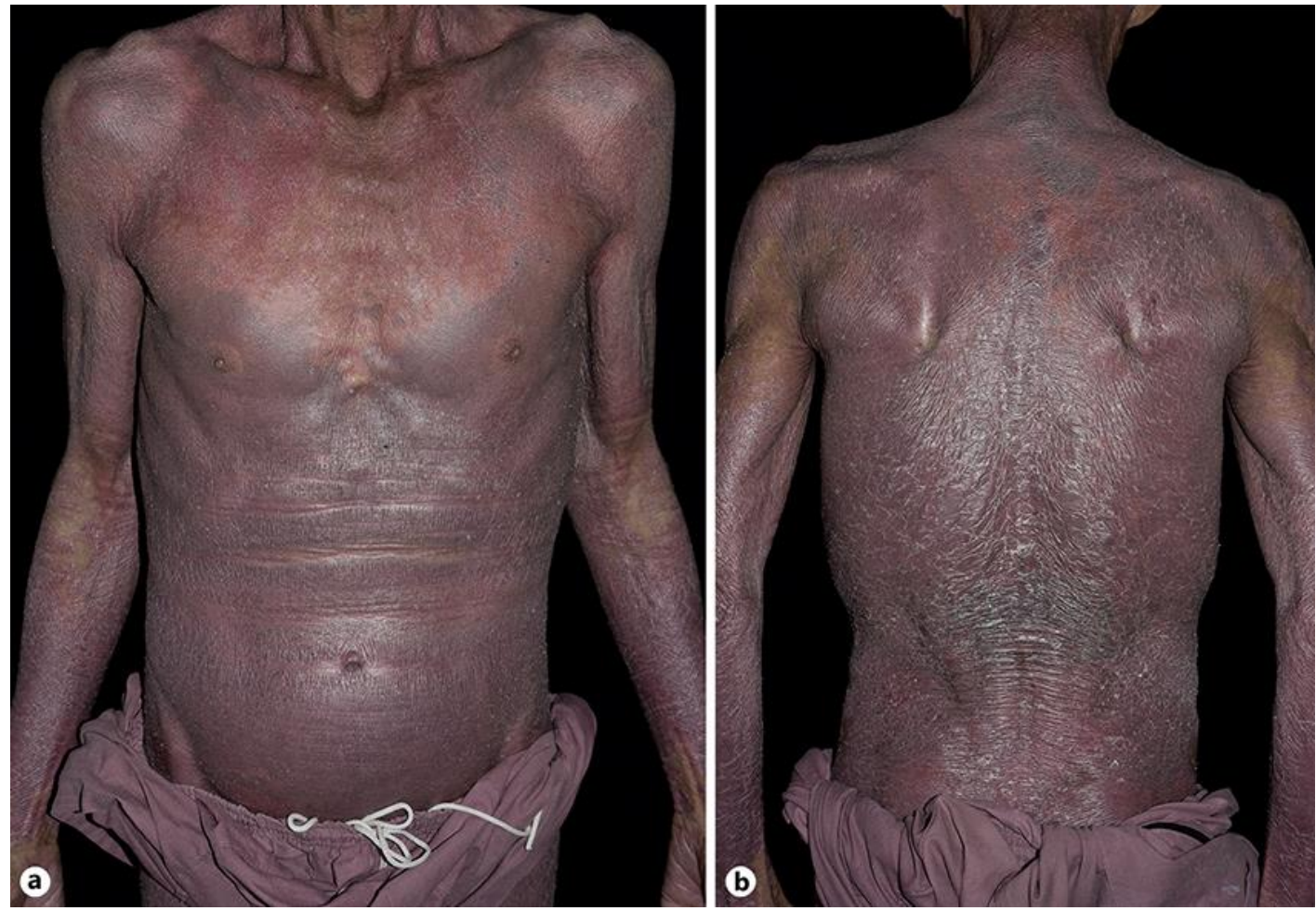

Fig. 1. Patient 1. a Baseline. b Two weeks after ixekizumab, $80 \mathrm{mg}$. 
Case Reports in Dermatology
Case Rep Dermatol 2020;12:132-137

DOI: $10.1159 / 000508781$ www.karger.com/cde

Pangilinan et al.: Anti-IL-17 Monoclonal Antibodies for Erythrodermic Psoriasis in HIV
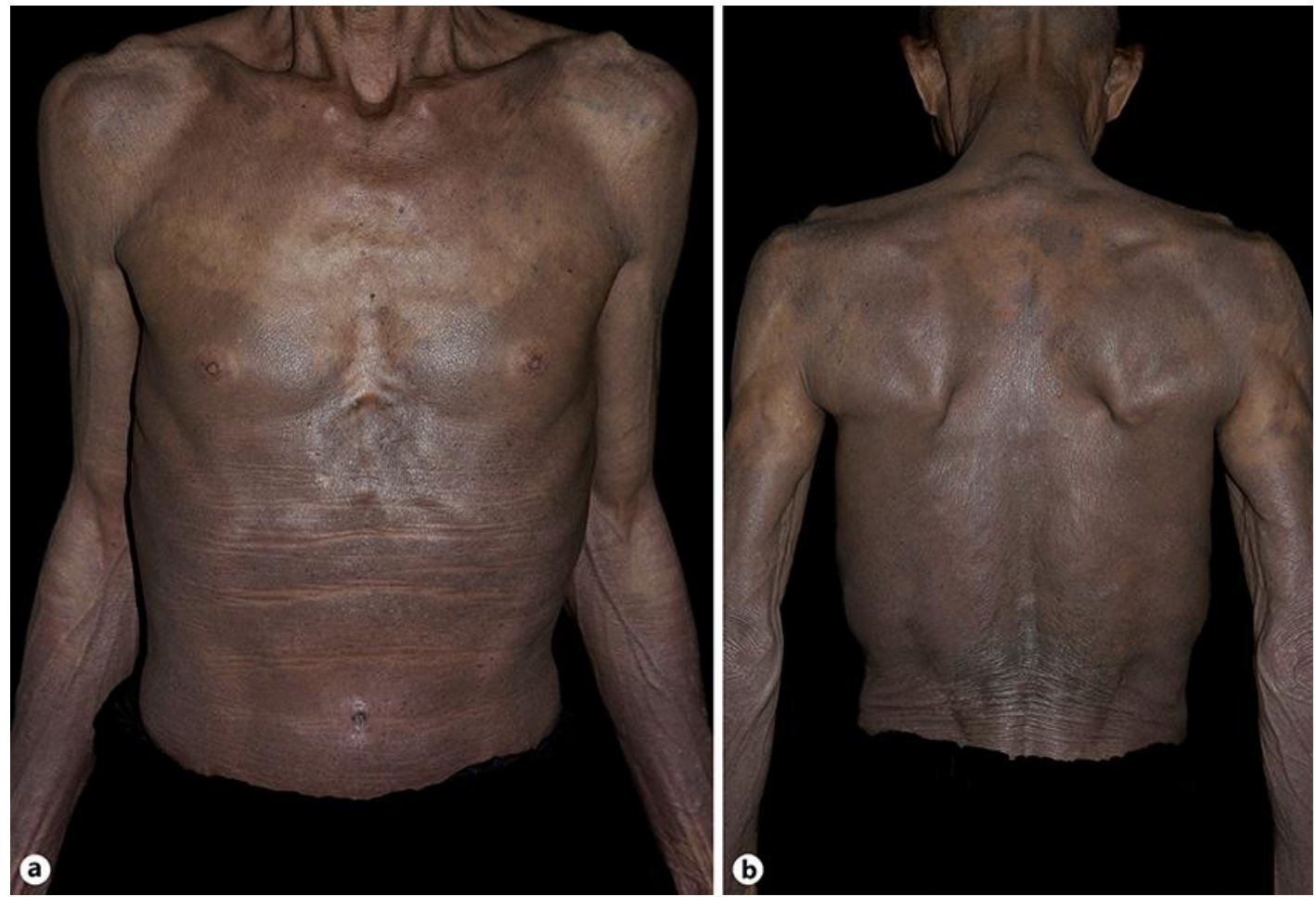

Fig. 2. Patient 2. a Baseline. b Four weeks into secukinumab, 300 mg weekly. 